\title{
A produção do conhecimento em Educação Física nos Estados de Alagoas, Bahia, Pernambuco e Sergipe (1982-2004)
}

Celi Nelza Zülke Taffarel

Diretora da Faculdade de Educação da UFBA Márcia Chaves Gamboa Pesquisadora voluntária do Paideia e colaboradora do LEPEL/UFBA Silvio Ancisar Sánchez Gamboa Professor do Defhe (Unicamp) e Coordenador Geral do Paideia

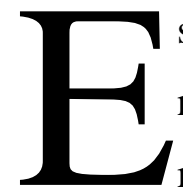
ste estudo sobre a produção científica em Educação Física nos Estados do Nordeste se situa dentro da pesquisa matricial do grupo LEPEL/UFBA (Linha de Estudos e

Pesquisa em Educação Física \& Esporte e Lazer), que integra estudos sobre as problemáticas significativas da produção do conhecimento em Educação Física.

O balanço crítico proposto, visando identificar tendências, perspectivas e desafios para a consolidação da produção científica na Educação Física no nordeste, foi orientado pela seguinte questão geral: Quais as características das dissertações e teses dos pesquisadores que atuam na área da Educação Física nos Estados de Alagoas, Bahia, Pernambuco e Sergipe no período de 1982-2004, identificando as problemáticas abordadas, as formas de tratamento teórico-metodológicas, as tendências epistemológicas, as propostas pedagógicas, sociais e políticas desenvolvidas, os compromissos com a problemática regional e as principais contribuições na compreensão da problemática da Educação Física nesses Estados?

Para a elaboração das respostas foram utilizadas informações sobre os pesquisadores (mestres e doutores) que atuam na região; sobre as pesquisas produzidas; sobre as condições da produção no contexto dos cursos de pósgraduação e do desenvolvimento da pesquisa em Educação Física no Brasil. Foram localizadas 145 pesquisas distribuídas nos Estados de Pernambuco (62), Bahia (35), Alagoas (23) e Sergipe (25). Desse total registraram-se informações de 122 pesquisas já defendidas (96 dissertações e 26 teses) e foram obtidas e analisadas 70: 58 dissertações, 11 teses de doutorado e 01 
(uma) de pós-doutorado, produzidas entre 1982 e 2004 (50\% nos 04 últimos anos).

Com base nas informações coletadas nos levantamentos e na leitura das dissertações e teses, as 70 pesquisas foram organizadas em dois tipos de agrupamento: $1^{\circ}$, com relação às áreas temáticas e $2^{\circ}$, em função das abordagens teórico-metodológicas identificadas através do esquema paradigmático.

Essas 70 pesquisas se distribuem assim: Pernambuco registra o maior número (26), 24 dissertações e duas (02) teses. Bahia registra (20) pesquisas, 15 dissertações, quatro (04) teses de doutorado e uma (01) de pós-doutorado. Alagoas registra (18) pesquisas, quatro (04) teses de doutorado e 14 dissertações, já Sergipe apresenta seis (06) pesquisas, uma (01) tese de doutorado e cinco (05) dissertações. As pesquisas abordam as seguintes áreas: memória, cultura e corpo (21\%), escola (20\%), formação profissional/campo de trabalho (19\%), políticas públicas (09\%), epistemologia (09\%), e atividade física e saúde (07\%), recreação/lazer $(06 \%)$, portadores de necessidades especiais $(04 \%)$, movimentos sociais $(04 \%)$ e rendimento de alto nível $(01 \%)$. 50\% das pesquisas atrelam-se às áreas, da memória, cultura e corpo, da formação profissional e da escola. $43 \%$ das pesquisas estão vinculadas aos grupos de pesquisa (LOEDEFE/UFPE e LEPEL/UFBA/UFAL e GEPEL/UFS) e 30\% das dissertações e teses foram organizadas em torno de uma orientadora responsável pela criação das primeiras redes de intercâmbio.

Com relação às fontes regionais localizam-se 11 pesquisas (15.7\%) sobre estudos gerais ou bibliográficos. 14 pesquisas (20.0\%) desenvolvem problemáticas localizadas, no Estado ou cidade onde o pesquisador realiza seus estudos. As 45 pesquisas (64.2\%) restantes demonstram um compromisso com os problemas da região. Dessa forma temos 27 estudos dedicados à problemática da Educação Física do Estado de Pernambuco, 08 de Salvador, 06 de Alagoas e 03 de Sergipe. 46\% dos pesquisadores da área se titularam em programas do nordeste em outras áreas como: Educação (UFPE: 20; UFBA: 06; UFPB: 02; e UFS: 02), Serviço Social (UFPE: 02) e Sociologia (UFPE 01). Como a região não possui programas na área de 
Educação Física, a maioria dos pesquisadores (51\%) se titulou em programas da área de educação, 06\% em outras áreas e apenas 43\% em Educação Física, em outras regiões do Brasil ou no estrangeiro. Destaca-se a abordagem crítico-dialética que pautou $46 \%$ da produção. Na seqüência a tendência fenomenológica (34\%) e finalmente, a abordagem empíricoanalítica (16\%). Os $04 \%$ restantes anunciam uma abordagem críticodialética, não apresentando as características da mesma. Com relação às técnicas de pesquisa foram priorizadas as qualitativas (79\%). As técnicas quantitativas foram utilizadas apenas por $04 \%$ das pesquisas e $17 \%$ utilizam as duas formas.

A produção, que abrange 22 anos, possibilita uma distribuição em três períodos: pioneirismo (1982-1992), expansão (1993-1999) e consolidação (2000-2004). Tal periodização, demarcada pela primeira dissertação defendida (1982), pela primeira tese produzida na região (1993) e pela consolidação de redes de intercâmbio e de grupos de pesquisa (2000) permite constatar tendências temáticas e epistemológicas e visualizar perspectivas.

Com relação às tendências teórico-metodológicas, a semelhança de outras regiões do país, constatou-se a diminuição das abordagens analíticas e positivistas e o aumento progressivo das tendências fenomenológicohermenêuticas e crítico-dialéticas.

O levantamento sobre pesquisas recentes ainda não analisadas e sobre projetos em andamento permitiu visualizar algumas perspectivas relacionadas com a consolidação da pesquisa na região e a criação de programas de pós-graduação. Foram identificadas 32 novas teses de doutorado (17 que já foram defendidas e $15 \mathrm{em}$ andamento) que, somadas às 11 já analisadas, indicam o potencial de doutores que atuam na região (18 em Pernambuco, 12 na Bahia, sete (07) em Alagoas, e seis (06) em Sergipe).

Esse indicador, somado aos 31 grupos de pesquisa, 21 deles (67.7\%) criados a partir do ano 2000, pode significar tanto a consolidação da pesquisa na região como a pulverização de esforços, na perspectiva de criação de novos grupos vinculados a cada novo pesquisador que se titula. Tal paradoxo pode comprometer a possibilidade de projetos articulados que 
visem à criação de programas de Mestrados na região. Nesse sentido, pode significar tanto uma possibilidade como uma dificuldade para superar o desequilíbrio regional, que exige, por um lado, a ousadia e otimização de recursos humanos e, por outro lado, a superação de individualismos em prol de projetos coletivos, interinstitucionais. Entretanto, o problema maior está na falta de políticas de desenvolvimento regional e da alocação de recursos para potencializar os esforços já acumulados. 